\title{
Correction to: Development of cytomegalovirus retinitis after negative conversion of cytomegalovirus antigenemia due to systemic antiviral therapy
}

\author{
Kayo Suzuki ${ }^{1}$ Kenichi Namba ${ }^{1} \cdot$ Kazuomi Mizuuchi $^{1} \cdot$ Daiju Iwata $^{1} \cdot$ Takako Ito $^{1,2} \cdot$ Keitaro Hase $^{1}$. \\ Nobuyoshi Kitaichi $^{1,2} \cdot$ Susumu Ishida ${ }^{1}$
}

Published online: 12 December 2020

(C) Springer-Verlag GmbH Germany, part of Springer Nature 2020

\section{Correction to: Graefe's Archive for Clinical and Experimental Ophthalmology https://doi.org/10.1007/s00417-020-05011-0}

The published online version contain mistake for the explanation of 'Zone 1'.

The correct presentation is given in this version.

The original article has been corrected.

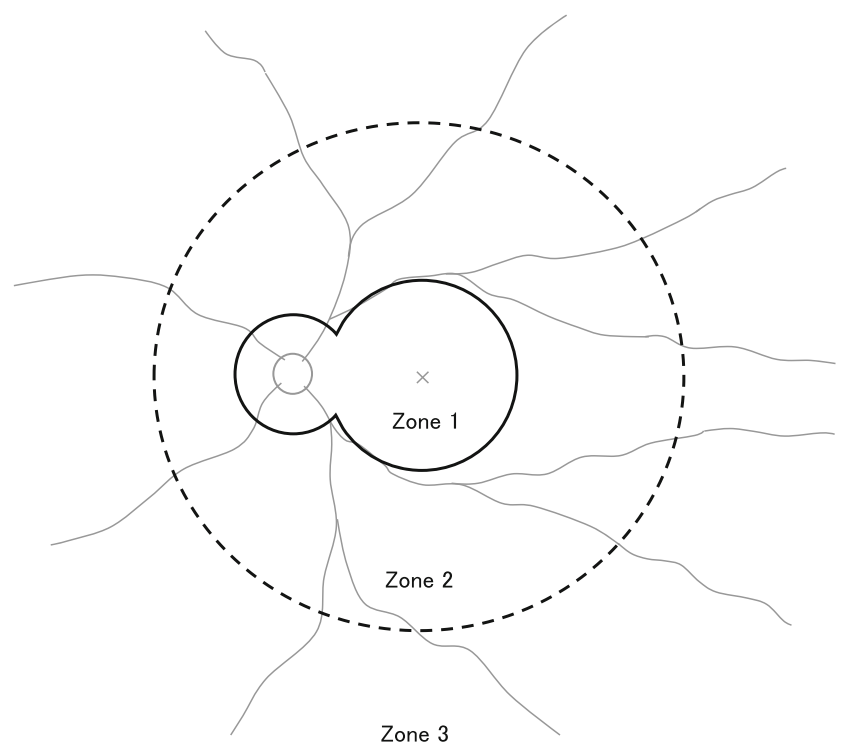

Publisher's note Springer Nature remains neutral with regard to jurisdictional claims in published maps and institutional affiliations.

The online version of the original article can be found at https://doi.org/10. 1007/s00417-020-05011-0

Kenichi Namba

knamba@med.hokudai.ac.jp
Department of Ophthalmology, Faculty of Medicine and Graduate School of Medicine, Hokkaido University, N-15, W-7, Kita-ku, Sapporo, Hokkaido 060-8638, Japan

2 Department of Ophthalmology, Health Sciences University of Hokkaido, Sapporo, Japan 